\title{
Present-Day Problems in Taxonomic and Economic Botany.*
}

\author{
By Dr. A. W. Hm., C.M.G., F.R.S.
}

TAXONOMIC workers have tended to fall 1 into one of two categories, for to some a 'species' has covered a wide range of forms grouped around a mean type, while others have taken a more restricted view and their species have represented far smaller and more sharply defined classificatory units. Both methods have been of value; the broader view has had its advantage very often in relation to questions of geographical distribution, while the narrower one has caused us to inquire into questions relating to the origin of species themselves and the significance of so-called 'varieties'. They have also had their drawbacks, since in one case many matters relating to the influence of habitat, general conditions, etc., have not been fully appreciated, while in the other the possibilities of hybridisation, segregation, and adaptation have usually received little or no recognition.

The intensive study of the flora of a region, or of particular genera, such, for example, as Rubus, Taraxacum, or Hieracium, has led in some cases, I feel, to the adoption of a very narrow outlook, which has tended to detract from the importance of taxonomic work in the eyes of the younger botanists. In the past, no attempt was made to study effects of light and shade or other environmental conditions, or to make cultural experiments to test the validity or otherwise of the find. Such experiments may involve controlled cultivation, genetical research, and very careful tabulation of statistics before full light can be shed on the true nature of what may have been regarded as a large 'compound-species' or a host of small, closely allied 'micro-species'.

Until I had the opportunity of visiting New Zealand I was not very greatly exercised about the problems underlying the species question, and was content, like others, to describe a new species from a single specimen. The extraordinary prevalence of hybridisation, however, in the New Zealand flora, seen under the able guidance of Dr. Leonard Cockayne, quickly made me realise how rash it would be to think of describing any New Zealand plant as belonging to a new species with only a single specimen before one. Here, then, is a large and vital problem which, to my mind, very greatly widens the interest and importance of our herbarium studies, since problems relating to the possible hybrid origin of the plants we are dealing with demand careful study in the field, with visits to the countries where the plants are native.

A somewhat parallel case, though of a different order, is afforded by the common mistletoe, Viscum album. Tubeuf gives an account of the races of Viscum album which are definitely associated with particular host plants. Three definite physiolological races, however, are clearly marked: (1) the form which is found on deciduous trees, (2) that

* From the presidential address to Section $\mathbf{K}$ (Botany) of the British Association, delivered at Bristol on Sept. 4. associated with the silver fir, Abies pectinata and other species of Abies, and (3) the form parasitic on Pinus sylvestris, $P$. Laricio, and $P$. montana. The races are so far distinct that seeds of the 'pine form', for example, will not grow on the apple or fir, and vice versa. Physiologically, therefore, they are distinct, though morphologically they cannot be separated. A case like this suggests that we may be witnessing the advent of three species from one, and that eventually morphological differences may also become evident.

The vegetation of South Africa supplies some taxonomic physiological problems of a like nature, which up to the present have not been satisfactorily solved. These relate to the difficulty of differentiating between two or more forms of the same species which, though distinct physiologically, cannot be separated on any structural characters. Several such physiological strains are now known in South African species of Pentzia and Salsola. There are two strains of Salsola glabrescens, which grow side by side. One of these plants, with purplishred young twigs, is closely grazed, while the other, in which the young twigs always appear to be pale-coloured, remains untouched by cattle or sheep until there is nothing else to eat. It would be of great interest, therefore, could we discover how the animals are able to distinguish the palatable from the unpalatable form, since we might then become as acute as they appear to be in appreciating the significance of fine distinctions.

Then again, there are puzzling problems connected with the character of certain species on different types of soil in South Africa: for a species may be a useful pasture plant on, say, a red loamy soil, yet when the same species, growing on tufaceous limestone, is eaten by stock, a heavy mortality may result.

It is also very remarkable that the Indian lac insect (Coccus lacca) has directed our attention to the existence of two physiological forms of Schleichera trijuga (Sapindaceæ), and to two forms of Butea frondosa (Leguminosæ), upon one of which it feeds while the other it does not touch; yet the botanist is unable to separate them in either case !

As it is so desirable that the importance and value of taxonomic work in its widest sense should be better appreciated in our schools and universities, I think it is worth while to say something as to what is now implied by taxonomy in the light of modern developments, in the hope that taxonomy, combined with ecology, may again occupy a prominent place in the studies of our developing botanists.

It is true, of course, that the taxonomist must know his plants and must be able, with careful training, to use to the full his powers of observation and deduction, so that he can appreciate small differences, weigh evidence, and draw up descriptions in comparison with allied species, etc.; but he will not go very far if he stops there.

No. 3178, Vor. 126] 
That we are appreciating now the problems surrounding every species which we are able to examine critically, through studying it in the field, and if need be under cultivation, is a healthy sign; for it is, I think, clear that the taxonomist, in undertaking experimental and field studies, will be able to throw much light on the ' origin of species ', and on the meaning and importance of the so-called 'variations' which such experimental study reveals.

This seeking after truth by means of experiment is not exactly a new development, though it may be claimed that the conception and planning, during the past few years, of new lines of inquiry has raised the status of these experiments to the definite plane of research. Isolated experiments to test the persistence of individual forms, varieties, or species have been made since Linnæus's day, but it is only in recent years that they have been carried out under careful control.

The classical experiments of Gaston Bonnier are well known. Daniel and F. Krasan have also published papers recording the direct influence of the environment on plant characters, but it is when we come to the work of Turesson in Sweden and Clements and Hall in America that the importance of transplant work to taxonomists, geneticists, and ecologists can be fully understood. The value of Turesson's work may be said to be that he has been able to come to conclusions as to the different types of variation shown by the plant he has observed, both growing wild and under cultivation, and has been able to demonstrate that in some cases they are of a heritable nature, while in others they are merely fluctuations.

These new lines of research, which bring together ecology, genetics, and taxonomy, are now being actively pursued at Potterne. Thanks to the kindness and keen interest of Mr. E. M. Marsden-Jones, the experiments are being made by him in his garden at Potterne, near Devizes, in co-operation with Dr. W. B. Turrill. Four large raised beds have been made side by side, and each has been filled with a distinct type of soil-clay, chalky clay, calcareous sand, and non-calcareous sand. On each type of soil twenty-five individuals of each of six species are now being grown, all being. of known genetic origin. Climatic conditions are being recorded, and full records of all features connected with the growth and behaviour of all the plants on the different soils are being kept. The species transplanted are Centaurea nemoralis Jord., Silene vulgaris Garcke, S. maritima L., Anthyllis vulneraria L., and Plantago major L., while during this year Fragaria vesca $\mathrm{L}$. has been added. It is interesting to find that the most obvious changes are taking place in Silene vulgaris, S. maritima, and Plantago major.

Centaurea nemoralis does not at present appear to be plastic ; Silene vulgaris is slowly plastic under certain edaphic conditions ; S. maritima is decidedly more plastic than its congener; Anthyllis vulneraria is not plastic, and is not capable of survival under a wide range of edaphic conditions, and Plantago major is exceedingly plastic.

In addition to what the taxonomist is seeking to discover from this intensive study of plants by means of 'transplant experiments', he is also anxious to elucidate the problems associated with certain 'critical' British and European genera, such as Silene, Centaurea, Rubus, Taraxacum, and Hieracium, in which botanists have described a multiplicity of species.

In the case of Rubus also it seems likely that carefully controlled experiments would possibly reveal the fact that habitat or hybridisation, rather than a 'fixed' type, was the raison d'être of several 'species'. Whatever research may reveal in these genera, it has been shown in Centaurea that at least three described 'species' are of hybrid nature, for exact counterparts of Centaurea jungens Gugl., $C$. pratensis Thuill., and $C$. Drucei C. E. Britt. have been artificially produced at Potterne.

An important development, arising out of the more intensive study of wild species and possible hybrids and the associated genetical work and controlled cultivation which is so pregnant of far. reaching results, is the need of greatly extended herbarium records and field notes. For genetical work to be of permanent value it is essential that ample material of the parent plants and their offspring should be preserved for reference; and in the case of assumed wild hybrids, representative specimens of the parents and of all the linking forms are required. I am glad to say that at $\mathrm{Kew}$ we have now established special 'herbaria' for genetical specimens and for hybrids, where specimens forming as complete a set as possible arekept together, apart from the general herbarium collection. We have also formed a collection of fruits and seeds, which it is hoped in course of time will be as comprehensive and complete as is the collection of the vegetative and floral specimens in the general herbarium.

Now let me turn to some problems on the economic side. In the first place, I would direct attention to the interesting observations made by Dr. A. B. Stout and others on the flower behaviour of Avocados, Persea gratissima Gaert. (Lauraceæ). These afford an excellent example of the assistance that the botanist can render to the grower and of the practical application of a remarkable botanical phenomenon of great scientific interest.

The Avocado pear bears hermaphrodite flowers, but they exhibit a daily rhythmic alternation of sexes reaching maturity for the entire plant. This synchronous dichogamy apparently reaches a perfection of phsyiological regulation to ensure crosspollination unknown in any other group of plants. All the flowers that may be open at any one time, on trees of the same clonal variety, are in either the female or the male condition. If the trees belong to one of the varieties placed in 'Class A' by Stout, of which the Taylor variety is taken as an example, the flowers when they first open in the morning are found to be functioning as females with a receptive stigma, but the anthers are not yet mature. About midday these female flowers close, for none but flowers in the female state are open on the trees, and another set of flowers then opens in the early afternoon, normally 
without any overlapping, so that there are never on any tree of 'Class $A$ ' flowers in the male and flowers in the female condition open at one and the same time. These afternoon flowers are found to be in the male condition with the stigma withered ; the anthers are in an upright position, with their valves open and shedding their pollen.

Careful investigation of trees of 'Class A' has shown that the flowers, when they first open, function as females for some four hours in the forenoon; they then close about midday, remain closed all night and all the following morning, and reopen on the afternoon of the second day in the male condition. Self-pollination of individual flowers is thus rendered impossible by this sex-alternation, and since there is normally a definite time interval, about midday, when no flowers on trees of the same 'Class' are open, cross-pollination on the same tree or between different trees of the same clonal variety can rarely occur.

This rhythmic phenomenon is all the more remarkable because there is an entire reversal of the process just described in other clonal varieties and individual seedlings, which Stout places in his 'Class B'. In trees belonging to 'Class B' the flowers are in the male condition when those of ' Class A' have their stigmas receptive, and are female when the pollen of 'Class $\mathrm{A}$ ' trees is being shed. These reciprocating changes in sex thus provide the opportunity for mutual cross-pollination between the trees of 'Class $A$ ' and those of 'Class B'. The practical application of this discovery scarcely needs pointing out, but it is clear that an orchard planted with trees of only one variety is not likely to yield a rich harvest of fruit!

With regard to pistachio nuts, which are grown as a crop in California, the problem facing the plant breeder, if he is to satisfy the grower, is to produce varieties bearing nuts which crack naturally. If varieties are produced the nuts of which have to be cracked by hand, they are of no value commercially, since the labour cost involved in cracking by hand in the United States is prohibitive if the nuts are to be sold at a profit! Fortunately, scientific research has now produced the desired article, and those who delight in pistachio ices, etc., can rest assured that they are coloured and flavoured by the genuine article and not by some synthetic product.

Limes, again, the staple industry of Dominica, present a curious and difficult problem. The wither-tip disease has made it imperative to carry out experiments with the object of producing races or varieties immune to the disease.

There seems good prospect of success attending these efforts. Dominica, however, is very hilly, and the lime bushes are grown on such steep hillsides that hand-picking of the fruit would be wellnigh impossible. The lime of commerce has the useful habit of shedding its fruit when ripe, so that the Dominican peasant merely has to go and collect the fruit under the trees or bushes. The problem before the plant breeder, therefore, is to produce a lime which not only is immune to disease but will also shed its fruit when ripe.
Unless this second essential can be attained, the new variety is of little or no commercial value.

Dr. Walter T. Swingle's researches on the pollination of the date palm (Phonix dactylifera L.) are of great interest:" Each species of Phœnix seems to have determined its peculiar action in ripening the fruit of the date palm. The amazing thing is that the pollen of the huge Canary Island palm used on the date palm produces a small seed, quite different from the ordinary date seed, and small or medium-sized fruit that ripens late, whereas the tiny palm $P$. Roebelinii, which has the smallest seeds of any Phonix, when used to pollinate the date palm, causes the formation of large seeds, and makes large dates which ripen extremely late." The economic importance and scientific interest of these discoveries need no comment.

Systematic botanists in the past have, I think, been rather too apt to regard the 'species' they have described as fairly definite units, recognising and recording from time to time 'varieties', but, as I have said earlier, frequently without sufficient material to enable them to say what such varieties really represent, or how constant and definite they may be. In some cases they may be the so-called 'Jordanons', while in others, no doubt, as we are beginning more fully to realise, they are the resultants of hybridisation. For the majority of plants the occurrence of such 'varietal' forms appears to be of little more than purely scientific interest, and they may be passed by with only a casual comment.

When, however, almost any plant comes into the limelight of applied botany and is found to be of some economic value, then the importance and significance of varietal differences at once become apparent. A few cases may be cited in illustration :

Para rubber (Hevea brasiliensis) is considered to be a good botanical species, but a careful examination of the trees now being grown in plantations in the East reveals a number of forms, very similar as regards their morphological characters, but showing marked physiological differences, especially with regard to the yield of latex.

A similar problem, where the systematic botanist requires the assistance of his economic colleague, has recently been investigated in Australia by Messrs. Penfold and Morrison. This concerns the oil yielded by Eucalyptus dives Schæur. $E$. dives is a species easy of botanical determination, and is of economic value for its oil, which has a piperitone content of about $\mathbf{4 5 - 5 0}$ per cent, which is used for the manufacture of thymol and menthol. Oil has been obtained yielding only 5-15 per cent of piperitone-morphologically, however, the trees were true $E$. dives-while others contain oil with less than 5 per cent piperitone and 45-75 per cent cineol. It might be thought that ecological conditions are concerned in these striking differences -for a typical form and three distinct physiological varieties have been recognised by their oil characters-but the type form with 40-50 per cent piperitone has been found growing alongside the variety $B$, containing only $10-20$ per cent piperitone with 25-50 per cent cineol. Here, then, is an

No. 3178, VoL. 126] 
interesting piece of investigation which brings the botanist into alliance with the chemist. A similar problem exists with regard to camphor, where, as is well known, two, and perhaps more, physiological varieties exist in the species Cinnamonium Camphora, which botanists are unable to separate.

Then again, the tung oil trees, Aleurites Fordii and $A$. montana, the seed of which yields a very valuable drying oil, are now being introduced through Kew and the Imperial Institute to all suitable Dominions and Colonies. In these trees the flowers are borne in clusters, and each flowercluster usually consists of a large number of male flowers surrounding a single female flower. It was noticed that certain trees bore two or three female flowers in each inflorescence. Selected seed from this 'multiple-cluster' type appears to transmit this characteristic, and trees showing this favourable variation may thus be expected to crop more heavily and yield more oil than trees with only one female flower in the cluster.

The problem, therefore, which may arise is analogous to that which confronts us with Para rubber in the matter of latex-yield or with cacao as regards permanent poor-yielders and permanent heavy-yielders. Cases such as these, and there are many others of a like nature, afford an apt illustration that economic and systematic botany can provide romances, possibly of more scientific interest to the botanist than to the commercial planter, but of so great material importance to the latter that the botanist looks to the man of affairs for the financial assistance to help him to discover their solution.

This brief summary will suffice to show that we are living in an era of progress and development, and that we are alive to the opportunities offered of widening our outlook and our interests in the domains of taxonomic and economic botany. As I have hinted earlier, our studies in taxonomic botany, to be living and of practical value, need to be transported from time to time from the herbarium to the field. In this way only can we realise fully the extent and character of variations, the effects of soils and climates, and the prevalence and significance of physiological races.

By the widening of our horizon through travel and by means of vegetational studies in the field, I feel myself on sure ground in maintaining that we are thereby more efficient, more enlightened, and more useful taxonomists, both in the pure and applied directions, than if our studies were strictly confined to the examination of the dried and mounted specimens in a herbarium.

Vast and enthralling as is the prospect, we seem somewhat to have failed to attract a sufficiency of able recruits. If this is so, then we must needs look for the reason. We may and, in fact, I think we are apt to say, like the "children sitting in the market-place', 'We have piped unto you and ye have not danced'; but with whom does the fault lie? May it not be, as regards taxonomic botany, that we have piped on a wrong note, that 'we have' in fact ' mourned' in a minor key; and have failed to pitch our tune on the high note of enterprise and endeavour?
Need I say I refer to the millstone of nomenclature, which encumbers and weighs down the neck of the systematic botanist. The theme itself, ' taxonomic botany' in its widest sense, is full of charm and interest, but it has been so obscured that many have failed to be attracted by the grandeur and harmonies of its melody. Much of our failure to attract disciples is due, I fear, to the misplaced activities of those whom I might call our taxonomic 'Scribes and Pharisees', who have tended to substitute the shadow for the substance. It remains for us to point the way and bring the labourers into the vineyard.

We are hampered to-day in our pursuit of scientific research by the all-important and interdependent problems of recruitment and remuneration. With regard to recruitment-and naturally I am speaking only with regard to botanical scienceare we fully satisfied with the efforts, laudable as they are, that are being made in our schools and universities, for training the rising generation in biological science? A good deal has been said recently about the advantages and disadvantages of early specialisation in science in the schools, at the expense of a more 'liberal' education. We realise that the last years at school are the time for laying the foundations of a sound education, and it is certainly a debatable matter whether the now prevalent severe competition (I might almost say scramble) for scholarships at the universities is not, after all, detrimental to the recruitment of those who should develop into the scientific naturalists for home and overseas appointments.

There is no question that the scientific training now given in many of the schools of Great Britain is of a very high order, and that it is given with the most splendid enthusiasm. But nevertheless may we not, owing to competition between school and school, be unduly forcing the pace and producing a superficial scientific precocity in our youth which will not stand the strain?

Science should not be looked upon as a task, but as a guiding tendency, for it is only by regarding it in this way that we can expect to produce the men with a true interest in and enthusiasm for scientific research. The flowering stage, so to speak, has been achieved before the roots and leaves have developed sufficiently to bear the fruit, and our young plants, raised from seed which may have fallen on stony places, will be found prematurely to wither away.

Then again there is a danger of the groundings of science being neglected at the universities, since there is a tendency to assume that the standard of school science teaching is that of the scholarship holder. There are, however, many who turn to science after they have had the good fortune of receiving a classical education, and I could mention botanists who only discovered their natural inclination and aptitude was towards science after they had entered the university.

There is still need to point out that the services which science can render, and for which there is so great a demand, cannot be obtained without making due provision for the cost. 